CDD: 128.33

\title{
Inferential Rationality and Internalistic Scarecrows
}

\section{Paulo Faria}

Federal University of Rio Grande do Sul

Department of Philosophy

Porto Alegre, RS - Brazil

paulo.faria@ufrgs.br

Received: 25.06.2015; Revised: 28.12.2015; Accepted: 31.12.2015

DOI: http://dx.doi.org/10.1590/0100-6045.2015.V38N3.PF

\begin{abstract}
In a recent paper, Manuel Pérez Otero attempted to turn the tables on Paul Boghossian's claim that content externalism is incompatible with the 'a priority of our logical abilities'. In reply, Boghossian argued that Pérez Otero's criticism misses the main point of his argument through concentrating on the semantics of singular (as opposed to general) terms. I elaborate on Boghossian's reply by showing that even taken on its own terms Pérez Otero's paper fails to engage with internalism through systematically misrepresenting what a truly internalistic account of the semantics of singular terms should be.
\end{abstract}

Keywords: Inferential rationality; Content internalism; Singular terms.

Paul Boghossian has recently replied to Manuel Pérez Otero's 'Boghossian's Inference Argument against Content Externalism Reversed' (See Pérez Otero 2014 and Boghossian 2014). The gist of Boghossian's reply is that his original 'inference argument' against content externalism was as much about general terms like 'water' as it was about singular terms like 'Pavarotti', on which Pérez Otero's criticism concentrates. The point of the argument was to show that content externalism 'blurs the distinction between an agent's mishandling the information she has, versus her merely failing to have the information.' (Boghossian 2014: 182). With that goal in mind, it would have been unwise to concentrate on singular terms, as the upholder of a 'direct reference' approach to such expressions might have no qualms about excluding beliefs involving singular terms from assessments of rationality and rational explanation, the way

Manuscrito - Rev. Int. Fil., Campinas, v. 38, n.3, pp. 5-14, set.-dez. 2015. 
we already do with de re beliefs. Such a strategy, though, could not be extended to the case of general terms, on pain of 'leaving nothing for assessments of rationality to be about.' (Boghossian 2014: 183)

I have no qualms with any of Boghossian's claims in his reply, but I think there is more to be said in criticism of Pérez Otero's imaginative - if, as I will claim, ultimately unsuccessful - effort. In particular, I think that even on his own terms - concentrating on the semantics of singular terms - Pérez Otero fails to keep the promise of a reversal of Boghossian's original argument.

That is not to say that everything is in order with Boghossian's argument, and nothing I will say should be taken as an endorsement of Boghossian's purported reductio of content externalism. All I am claiming is that Pérez Otero's attempted peritrope fails; and that the failure is instructive. I briefly sketch my assessment of where that leaves us by the end of this paper.

The aim of Pérez Otero's paper is to turn the tables on Boghossian's claim (as argued for in Boghossian 1992 and 1994) that content externalism is incompatible with the 'a priority of our logical abilities'. Its main thesis is that 'the problematic situation that Boghossian describes represents an important challenge for any theory of content, not just for externalism' (Pérez Otero 2014: 182). Moreover, it is Pérez Otero's contention that 'to the extent that the problem bears on the externalism/internalism debate, it is the externalist side that comes out on top.' (Ibid.)

With that aim in view, six conjectural 'internalist solutions' to Boghossian's challenge are reviewed, all of which are found (reasonably enough in each case) wanting.

In counterpoint, two externalist responses are reviewed, both of them (in contrast with the suppositious 'internalist solutions' devised by Pérez Otero) actually put forward in the literature. (These are the Schiffer-Burge 'anaphorical' account of content preservation and the 'logical luck' approach pioneered by Sorensen ${ }^{1}$ ). The comparison is claimed to establish the stronger thesis that Boghossian's argument is more problematic for internalism than it is for externalism.

These are bold and surprising claims, yet I cannot see that Pérez Otero manages to make them good. And that comes from what I cannot help seeing as a deep flaw in the whole conception of the paper. To put it in a nutshell, the

${ }^{1}$ See Schiffer 1992, Burge 1998, Sorensen 1998, and Faria 2009.

Manuscrito - Rev. Int. Fil., Campinas, v. 38, n.3, pp. 5-14, set.-dez. 2015. 
review of the six so-called 'internalist solutions', which bears Pérez Otero's burden of proof, is, I'm afraid, a paradigm case of shooting at scarecrows of one's own contrivance, devised and customized, as it were, for swift dismissal.

That this is the case is brought to the fore by noting that all of the six internalistic responses devised by Pérez Otero share the common weakness of granting to externalism a crucial assumption which, intuitive as Pérez Otero (and, presumably, other friends of externalism) may find it, no clear-sighted internalist should embrace (and none, to the best of my knowledge, has ever actually embraced): namely that contextual factors such as highlighted in Twin-Earthstyle thought experiments are apt to impinge upon the reference of such ostensibly non-indexical terms as (in Boghossian's 'Pavarotti' case, on which the paper concentrates) proper names.

Now Pérez Otero is persuaded that 'with respect to singular terms, our externalist intuitions (as highlighted by Putnam and Burge in their thought experiments about Twin Earths) are even stronger than they are with respect to natural kind terms (which are usually evoked to illustrate the discussion).' (2014: 161). And again: 'the original externalist intuitions invoked by Putnam to support the idea that an external factor - the reference of 'water' - contributes to determining the meaning of 'water' are also present, and more obviously so, in the case of singular terms such as 'Pavarotti'.' (2014: 177). Ultimately, 'it is the common, externalist intuitions (that were invoked by Putnam and Burge in their original thought experiments) that tip the balance in favour of externalism' (2014: 180).

No evidence is provided, however, for the tacit assumption that such intuitions are shared by any writer in the internalist camp - and I doubt that any could be found. Actually, the closest that Pérez Otero comes to discharge that burden of proof surfaces in the utterly misguided (and no sooner entered than cautiously hedged) remark that 'Boghossian explicitly states' (2014: 169) that the reasoner in his original example falls prey to a fallacy of equivocation (as his two successive tokenings of 'Pavarotti' would fail to refer to a single individual, courtesy of his having been 'slow-switched' from Earth to Twin Earth). Now, to be sure, Boghossian 'explicitly states' that - but only as a step in a reductio argument: something that externalists are (allegedly, anyway) committed to hold. That much does not escape Pérez Otero's notice (see 2014: 169-170); indeed, failure to see the point would amount to entirely miss the dialectics of Boghossian's argument. In spite of which the claim that Boghossian 'explicitly 
states' that the inference performed by the reasoner in his original example is invalid recurs - as 'a wheel turning idly', to borrow Wittgenstein's phrase - twice along the paper (see 2014: 172, 174).

Two remarks are in place here. First, the claim that externalists are committed to hold that slow-switching is apt to impinge upon the semantics of proper names is not essential to Boghossian's argument; the claim was assumed for the sake of the argument, and is disposable in a way that the parallel claim about general terms is not. In other words, the real battleground between externalism and internalism is conceptual content, not singular reference. In his reply, indeed, Boghossian explicitly acknowledges that any examples of alleged equivocation involving names may be effectively neutralized by the externalist who is prepared to take seriously the idea that sentences containing proper names express object-dependent propositions: 'If my problem-generating example had involved only names, an externalist would have an easy and conservative way out of the problem: treat beliefs involving names in the way that we already treat de re beliefs, by selectively excluding them from assessments of rationality and rational explanation. Such a maneuver may not be cost-free, but it's in the running.' (2014: 183).

Second, there are, and so much is common ground between Boghossian, Pérez Otero and the present writer, other strategies that an externalist may adopt to deal with Boghossian's challenge. It may be denied that Burgean 'slow switching' scenarios allow for undetectable fallacies of equivocation. Slow switched Peter remembers, from his childhood on Earth, that he used to enjoy playing in water. Turning his attention to a glass full of a transparent liquid now lying on his Twin Earthian desk, he reasons from (1) 'I enjoyed playing in water when I was a kid' and (2) 'This glass is full of water' to the false conclusion (3) 'This glass is full of the same liquid I enjoyed playing in when I was a kid' - false, no doubt, as twater $(X Y X)$ is not water $\left(\mathrm{H}_{2} \mathrm{O}\right)$. Now, to be sure, Boghossian has the externalist taking 'water' to mean $\mathrm{H}_{2} \mathrm{O}$ in (1) and $\mathrm{XYZ}$ in (2), which makes Peter's inference invalid; hence the claim that content externalism puts in jeopardy the 'a priority of our logical abilities'. But it is open to the externalist to claim that 'water' is univocal throughout the reasoning, either by taking its extension to have been fixed by the earlier, Earthian uses (as on the SchifferBurge 'anaphorical' account of content preservation, cf. Schiffer 1992, Burge 1998), or else by taking it to be fixed relatively to the environment in which the reasoning takes place (as on Ludlow's 'ecological' take on preservative memory, 
cf. Ludlow 2004). On the first alternative, (1) would be true and (2) false; on the second alternative, (1) would be false and (2) true; either way, the inference would be valid and Peter's rationality would be secure. A third alternative, so far the road less travelled by, would bite the bullet about Peter's equivocation, urging us to accept that, as Timothy Williamson argues, 'the external individuation of content makes the deductive validity of inferences imperfectly accessible' (Williamson 2000: 16). In other words, granted, to the likes of Boghossian, that content externalism is indeed incompatible with the 'a priority of our logical abilities', so much the worse for the latter. That is, in particular, the gist of the 'logical luck' response to Boghossian's challenge, briefly discussed, and out of hand dismissed, by Pérez Otero in his paper. As Boghossian aptly summarizes it in a more recent paper: 'Sorensen (1998) and Faria (2009) have suggested that it is [the assumption that Peter is a fully rational agent] that has to go. Being rational, they say, just like being moral, is a matter of luck. And Peter is unlucky.' (Boghossian 2015: 101).

Now Pérez Otero's argument is conditional: if there is a problem with reconciling externalism and the 'a priority of our logical abilities', then internalism faces the very same problem; and that is so because 'our externalist intuitions' with respect to the semantics of singular terms 'are even stronger than they are with respect to natural kind terms' - strong enough, anyway, to constrain every possible internalist construal of that semantics. Or so Pérez Otero would have us think - without benefit of evidence, I stress, as none is provided for the claim.

Armed, then, with 'our externalist intuitions', and failing to come up with any real life target, Pérez Otero proceeds to devise 'internalist solutions' to Boghossian's challenge which, being equally (if variously) blemished by the tacit acceptance of those 'externalist intuitions', are easily shown to be less plausible than the preferred externalist analyses.

A sensible internalist take on the issue, however, will have none of such 'externalist intuitions'. Suppose, to indulge in the standard fantasy, that I am stealthily taken overnight, while sound asleep, to Twin Earth. Next morning I awake in twin home on twin bed and, sure, everything looks exactly the same. Sometime later, while still dwelling on Twin Earth, I attend to a very interesting lecture by a philosopher who (unbeknownst to me, of course) turns out to be Ernest Sosa's Twin Earthian Doppelgänger. Relying on my memory, I reason afterwards as follows: 'Ernest Sosa attended the 2011 Rutgers Epistemology Conference. The philosopher I've heard today is Ernest Sosa. Therefore, the 
philosopher I've heard today attended the 2011 Rutgers Epistemology Conference'. What should an internalist say about the reference of 'Ernest Sosa' as tokened in each premise, and then about the validity of the inference? No doubt, that in both cases the reference of the name is the Earthian philosopher; that the second premise is false (as I plainly mistake someone else for Ernest Sosa); and that the reasoning is valid, its false conclusion being correctly drawn from a set of premises one of which is unfortunately false. The case is philosophically no more vexing than the outcome of taking a Hyllary Clinton lookalike for Hyllary Clinton.

Notice, in passing, that the view that the name will have been used univocally throughout the reasoning is independent of the choice of any particular theory of reference among those which may be available to the content internalist: whether the reference of a proper name is determined, say, by a Fregean sense, or else by a Kripkean historical chain of communication, the only fixed point is that it is not apt to shift (as Pérez Otero's 'externalist intuitions' intimate) as the user of the name moves from context to context. It is worth stressing, in particular, that a Kripkean chain is maintained by each speaker's intention to use the name in conformity with its previous uses, and on an internalist construal such intention will be as internal (as much 'in the head', in Putnam's phrase) as a Fregean sense. ${ }^{2}$

\footnotetext{
${ }^{2}$ Lest there be any doubt about such appeal to the speaker's intentions, here is Kripke himself: 'When the name 'is passed from link to link', the receiver of the name must, I think, intend when he learns it to use it with the same reference as the man from whom he heard it.' (Kripke 1980: 96.) And then on the next page: 'Notice that the preceding outline ... takes the notion of intending to use the same reference as a given.' (Kripke 1980: 97). A very perceptive referee for this journal objected at this juncture that 'what a speaker's intentions determine is not the identity of the object referred to but her adequate insertion in the communication chain'. To which the appropriate reply is that the two go together: the speaker will not be adequately inserted in the communication chain, and thereby will not be referring to the right object, unless she intends to use the name with the same reference as those from whom she inherits it; in other words, adequate insertion in a communication chain, and thereby success in referring to the right object, involves deference to predecessors in the chain. Now reference fixing, which inaugurates the chain, involves, to be sure, more than speaker's intentions; and to that extent, no doubt, the identity of the object referred to is not sufficiently determined by such intentions. That is generally true even as reference may be fixed by description, rather than by ostension (or, if you like, acquaintance) and in the absence of any causal
} 
Neglecting, courtesy of 'our externalist intuitions', this plain, sensible (and, for once, truly internalistic) construal of Boghossian's scenario, Pérez Otero goes on to review the six 'internalist alternatives' of his own devising, only to find them, unsurprinsingly enough, 'less plausible than externalist analyses'.

The first alternative comes closer than any of the remaining five to internalist sanity in holding that 'a singular term such as 'Pavarotti' expresses the same concept, whether it is used on Earth and on Twin Earth, and the same reference also corresponds to that concept' (2014: 169); yet, bending to the pervasive 'externalist intuitions' which vitiate the whole discussion, it is also part of the thesis that 'the premises and the conclusion [of the inference performed by Peter, the slow-switched reasoner in Boghossian's original example] are all true, so there is no problem attributing logical validity to Peter's inference' (2014: 169). The joint satisfaction of these two ostensibly conflicting claims is secured by a quite extraordinary view, which Pérez Otero appositely describes as leading 'to a very extravagant semantics, or to a very extravagant ontology; or to both' (2014: 170): namely, that the referent of the name is neither the Earthian nor the TwinEarthian Pavarotti but something like the aggregate or fusion (however conceived) of the two singers: 'To be the singer Pavarotti is conceived in such a

interaction with the object (think of Leverrier's 'Neptune'): after all, the description must not be empty (think, by contrast, of Leverrier's 'Vulcan'), and that is a matter of how things are in one's environment. (But then, let me add in passing, the same goes for whether a Fregean sense determines a reference: so far the two views are exactly on a par.) Likewise, ostension must, on Kripke's account of reference fixing, succeed in actually singling out an object for a naming to take place; and that is, again, a matter of how things are in one's environment (together with how things are about one's epistemic position with respect to that environment). But then it is by no means my claim that Kripke's appeal to speaker's intentions would amount to (in my objector's words) 'an internalistic construal of reference determination'. My claim is that a non-descriptivist approach to the semantics of proper names is available to the internalist as much as to the externalist; in other words, that 'direct reference' (by any other name) may be accepted on grounds (such as, most notably, Kripke's Modal Argument) which owe nothing to what Pérez Otero calls 'our externalist intuitions'. No more is needed, and accordingly no more is claimed, for the purpose of this paper. 
way that not only does such a property apply to both Pavarotti and twin Pavarotti, but it applies to both of them as the same singer.' (Ibid.)

That way, to be sure, madness lies, and so oddly contrived an 'internalist solution' is rightly dismissed as an admissible candidate to account for Boghossian's scenario; and ditto for each of the remaining five alternatives devised by Pérez Otero on behalf of his internalist adversaries. If, however, I am right in claiming that no sensible internalist should partake of the 'externalist intuitions' which likewise constrain the conception of each of these remaining 'internalist alternatives', I suppose I may be excused from discussing them in any detail. Just for the record, at any rate, here they are:

(i) 'Pavarotti' expresses an 'amalgam concept', modelled upon Putnam's 'jade': its extension comprises both Pavarotti and Twin Pavarotti;

(ii) 'Pavarotti' is an indexical: it has the same Kaplanian character on Earth and Twin Earth, yet that character is not enough to determine its reference;

(iii) 'Pavarotti' is a 'context-imprinting indexical', by which Pérez Otero means a curious sort of indexical such that its reference would be determined by the first context of its use, and remain invariant thereafter. (In fairness to Pérez Otero, let it stand on record that he remarks, sensibly enough: 'Maybe there are no context-imprinting indexicals in natural language. Neither is it clear why it would be useful from a functional point of view to have them.' (2014: 174))

(iv) 'Pavarotti' is an indexical, as in (ii), but its reference throughout a single chain of reasoning is held fixed by the subject's intention to refer to the same individual, which (as in the Schiffer-Burge externalist response to Boghossian's challenge) would secure that, once used (to refer, as the case may be, either to Pavarotti or to twin Pavarotti), its later occurrences will be anaphoric upon that reference-fixing antecedent.

(v) The two occurrences of 'Pavarotti' have different contents (as accords with the 'externalist intuitions'), but their difference will depend on internal factors, accessible to the subject, who will then be in a position to avoid such errors in reasoning as featured in Boghossian's argument.

I should say in conclusion that, like Boghossian (see his 2014: 184), I think Pérez Otero is right in claiming that the problem of transparency of logical form is a challenge to any theory of content, not just to externalism; and moreover, that (unlike Boghossian) I am persuaded that at least some of the extant externalist strategies are more likely to cope with the problem than even the "real life" internalist strategy I described above. I have elsewhere defended 
one such externalist strategy myself (I took the road less travelled by - see above - and, yes, it made all the difference); but this is not the place to do it again. ${ }^{3}$

\section{References}

Boghossian, P. A. 'Externalism and Inference', Philosophical Issues 2: 11-28, 1992.

. 'The Transparency of Mental Content', Philosophical Perspectives 8: 33-50, reprinted in Content and Justification (Oxford: Clarendon Press, 2008): 159176, 1994.

. 'Reply to Otero's “Boghossian's Inference Argument against Content Externalism Reversed"', Philosophy and Phenomenological Review 89: 182-184, 2014.

. 'Further Thoughts on the Transparency of Mental Content' in Sanford C. Goldberg (ed.), Externalism, Self-Knowledge, and Skepticism: New Essays (Cambridge: Cambridge University Press): 97-112, 2015.

Burge, T. 'Memory and Self-Knowledge', in P. Ludlow \& N. Martin, eds. Externalism and Self-Knowledge (Stanford: CSLI): 351-370, 1998.

FARIA, P. 'Unsafe Reasoning: a Survey', Dois Pontos 6: 185-201, 2009.

KRIPKE, S. A. Naming and Necessity (Cambridge, MA: Harvard University Press), 1980.

LuDLOW, P. 'What Was I Thinking? Social Externalism and Shifting Memory Targets', in R. Shantz (ed.), The Externalist Challenge (Berlin: De Gruyter): 419-426, 2004.

\footnotetext{
${ }^{3}$ I am grateful to Paul Boghossian for discussion of issues broached in this paper, and to an anonymous referee for this journal for helpful comments on a previous draft. Work on the paper was supported by a grant from the National Council for Scientific and Technological Development - CNPq (Grant \# 302583/2013-0).
} 
Otero, M. P. 'Boghossian's Inference Argument against Content Externalism Reversed', Philosophy and Phenomenological Review 89: 159-181, 2014.

SCHIFFER, S. 'Boghossian on Externalism and Inference', Philosophical Issues 2: 2938, 1992.

Sorensen, Roy A. 'Logical Luck', The Philosophical Quarterly 48: 319-334, 1998. 